\title{
COMMENTARY
}

\section{GLUCOSPHINGOLIPIDS AS SITES OF ACTION IN THE CHEMOTHERAPY OF CANCER}

\author{
NORMAN S. RADIN* and JIN-ICHI INOKUCHI ${ }^{*}$ \\ Mental Health Research Institute, University of Michigan, Ann Arbor, MI 48109, U.S.A.
}

Searches for abnormalities in tumors have revealed a dismayingly large number of metabolic changes, both increases and decreases in the content of qualitatively normal substances. Substances having a novel chemical structure have been found only rarely. The possibility should be considered that these apparently new compounds, despite their variety and inconsistency of appearance, are somehow responsible for the unrestrained growth, malignancy, and invasiveness characteristic of cancer. A corollary possibility should also be considered: certain admittedly normal substances found in tumors in relatively high concentrations can, if they reach a triggering concentration, begin the cancerous process.

This paper presents selected clues about a class of compounds in the above categories, the glycosphingolipids based on GlcCer. $\neq$ They are called "glucosphingolipids" in the title and "glycolipids" in the text. $\$$ These substances are formed from $N$-acyl sphingols (ceramides) by a transferase which attaches glucose to the C-1 of the sphingol. Other transferases subsequently attach additional sugar groups to the GlcCer. The most-studied glycolipids are the ones containing sialic acid, the gangliosides. Acetyl groups can be present in amide and ester linkage, and glycolyl groups can be present in amide linkage.

Many researchers have come to believe that glycolipids are "closely involved" in one or more aspects of cancer cell metabolism and this article summarizes some of their reports. On the basis of literature reading and initial success with a drug that inhibits glycolipid synthesis in mouse Ehrlich ascites tumor cells, we have come to believe that glycolipids are causally involved in cancer. Our hypothesis starts with the recent discoveries that some types of cancer

* Send correspondence to: Dr. Norman Radin, Neuroscience Laboratory Building, The University of Michigan, 1103 East Huron, Ann Arbor, MI 48104-1687.

$\dagger$ Present address: Faculty of Pharmaceutical Sciences, Fukuoka University, Nanakuma 8-19-1, Jonan-ku, Fukuoka 814-84, Japan.

$\ddagger$ GlcCer = glucosylceramide or glucocerebroside.

$\$$ The other major glycosphingolipid family consists of the galactolipids, particularly galactosylceramide and sulfatide. They have not yet been implicated in cancer. are apparently due to inactivating damage to, or deletion of, both copies of a specific gene on one chromosome or another, depending on the particular tumor [see, for example, Refs. 1 and 2]. The double defect can be of prenatal origin, of postnatal origin, or both. Thus, these-or all-forms of cancer may be due to a lack of a specific protein normally produced by the affected cells. The lack needs to occur in only one cell, and the missing protein apparently cannot be furnished by surrounding normal cells.

In the next stage of our hypothesis, we postulate that the missing protein acts in normal cells to hydrolyze a specific glycolipid that is normally present at a very low concentration. A cell unable to hydrolyze the lipid would then become a cancer cell, accumulating relatively large amounts of the glycolipid, which acts to initiate its fatal proliferation. Feedback mechanisms to block the accumulation of glycolipids apparently do not exist, judging by sphingolipidosis patients. The lipid may normally function in promoting growth or differentiation or cell adhesion; alternatively, it may have no normal or important function, just as (the nonenzymatically produced) crcatinine and glucosylated hemoglobin seem to have no metabolic functions. Only when its concentration becomes elevated does the lipid take on a primary neoplastic role.

According to this hypothesis, cancer is a glucosphingolipidosis of a single cell, with a great variety of secondary effects which depend on the cell type and the specific gene deletion. The secondary effects could appear as physical changes in the properties of specific membranes and their receptors, as stimulatory or inhibitory effects of the accumulating lipid on the activities of several enzymes, as induction of the synthesis of various proteins, and as changes in the rates of synthesis or breakdown of sphingolipidmetabolizing enzymes. Widely varying secondary phenomena are characteristic of the genetic sphingolipidoses, despite the simplicity of the genetic defects, and it appears that each sphingolipid controls many different functions.

In the case of tumors caused by mechanical loss of the allelic genes via a chromosomal break, several additional proteins coded for by adjacent genes would also be missing, adding additional variety to the manifestations of the individual patient's tumor. 
Where radiation, a carcinogen, or a virus is involved, one could postulate that such agents can ultimately damage both genes in one particular cell. Cells with only one gene damaged would become cancerous if the companion gene was genetically defective, a type of genetic predisposition. The loss of hydrolytic activity need not affect the identical glycolipid in every type of tumor; there is evidence that different glycolipids can have similar roles in malignancy, depending on the cell type. One could propose that oncogenes act by inactivating the particular glycolipid hydrolase, an idea consistent with experiments cited below $[3,4]$.

A double deletion of this nature could, in some patients, involve the loss of an activator protein for the glycolipid hydrolase. Three activator proteins for known glycolipid hydrolases have already been found, and there are undoubtedly others to be discovered. Still other forms of cancer could arise from loss of a specific carrier protein, which normally may act to bring the lipid to a hydrolase. Glycolipid transport proteins are known to exist. One can imagine additional ways in which a specific hydrolase might become ineffective or in which the accumulated glycolipid might become more or less effective in inducing the neoplastic state.

While many glycolipids have been found to be associated with tumors, it is possible that only a few of them are causally involved. The actual neoplasmproducing compounds have perhaps not been correctly identified because of (1) the contaminating presence of other glycolipids that have similar chromatographic characteristics, (2) their complexity of structure, and (3) their low level of occurrence (even when found in relatively high concentrations). Glycolipid chromatography is still in a primitive state.

An important test of our hypothesis would be the demonstration that a glycolipid hydrolase is largely or completely absent from a tumor but present in the tissue of tumor origin. This could be done by seeking specific hydrolases, using natural substrates (preferably the novel or unusual glycolipids characteristic of the specific tumor being studied). The common practice of assaying for hydrolases with unnatural substrates, such as nitrophenyl glycosides, is unsatisfactory since they are probably each hydrolyzed by several different enzymes. The addition of bile salts as enzyme stimulators should not be relied on, since they may hide the lack of a natural hydrolase activator.

The following sections summarize-all too concisely - a few of the findings which lend support to this set of speculations. Some of the topics have been touched upon in greater depth in previous reviews. In our conclusion we propose chemotherapeutic approaches based on these ideas.

\section{A. The proliferating effects of glycolipids}

A major clue comes from patients with Gaucher disease, a genetic disorder characterized by a low level of GlcCer glucosidase activity and accumulation of very high levels of GlcCer. Reports have appeared pointing to an unexpectedly high incidence of leu-

* Agranoff BW, Heacock AM, Vunnam RR and Radin NS, unpublished work. kemia and other disorders of B-cell proliferation [5-7]. The high content of tissue GlcCer in these patients, it has been suggested, somehow overstimulates B-cell proliferation with consequent malignant or benign transformation [6].

Gaucher patients not only accumulate high concentrations of GlcCer, but they also suffer from severe hypertrophy of the spleen and liver. These organs are the primary sites of blood cell destruction. a process which includes GicCer hydrolysis, so they normally have a relatively high hydrolytic workload. When the hydrolase is defective, Glocer accumulates. A similar phenomenon occurs in some patients with chronic leukemias, which apparently overload the capability of their glucosidase [8]. We suggest that the extra GlcCer somehow, in a relatively direct way, acts to produce splenic proliferation.

We have found that injecting young mice with emulsified or liposomal GlcCer causes rapid growth of the liver as well as marked uptake of GlcCer [9]. The growth is accompanied by a correspondingly increased formation of protein, lipid, and DNA and elevated levels of enzymes involved in DNA synthesis. Thus, the growth stimulation seems to be of a proliferative nature. The effect is stronger (up to $25 \%$ growth in 1 day) when we also inject conduritol $\mathrm{B}$ epoxide, which blocks the catabolism of GlcCer by inactivating GlcCer glucosidase. GlcCer or one of its metabolic products can be considered to be a mitogen which normally occurs at very low tissue concentrations.

In vitro, ganglioside stimulated axonal sprouting in neuronal cultures [10]. Conversely, an inhibitor of GlcCer synthesis inhibited axonal sprouting in retinal cultures. * A specific ganglioside, GQlb, was found to increase the number of neuroblastoma cells and their neurites [11]. The $B$ subunit of cholera toxin, which specifically binds to endogenous ganglioside GMl, produced thymocyte proliferation, suggesting that activation of the binding site containing GMI results in growth stimulation [12]. The proliferative action of the toxin/receptor complex may arise through its ability to raise local cyclic AMP levels [13]. A mixture of gangliosides was found recently to stimulate the growth and metastasis of human and rat tumors in nude mice [14]. The ability of weakly tumorigenic AKR lymphoma cells to proliferate after implantation into mice was enhanced greatly by adding the gangliosides which had been secreted by a highly tumorigenic cell line of the same strain [15]. Thus, the glycolipids that are more glycosylated than GlcCer can also exert a proliferative effect in vitro and in vivo.

We found that the growth of mouse ascites cells (Ehrlich carcinoma) could be enhanced $>50 \%$ by injecting GlcCer intraperitoneally [16]. Conversely, an inhibitor of GlcCer synthesis blocked the growth of the cells. One might conclude, at least in the case of these cancer cells, that the tumor's speed of synthesizing this lipid is rate-limiting in the growth process.

Another similarity between Gaucher disease and cancer comes from the observation that the concentration of ferritin (the iron-storage protein) is very elevated in both kinds of tissue [17]. 


\section{B. The occurrence of new glycolipids}

It has been known for many years that certain tumors contain normal glycolipids ("cytolipins $\mathrm{G}, \mathrm{H}$, K"), but at abnormally high levels. More recently, ganglioside GM1 or GM3 was found at a high level in human meningiomas when compared to normal meninges [18]. In a different study, human leukemia cells were found to contain ganglioside GD3 whereas normal leukocytes did not contain detectable amounts of this lipid [19]. A study of neuroblastomas from fifty-three patients concluded that the prognosis of a patient could be correlated with the tumor's content of ganglioside GT1b [20]. Thus, a tumor can contain a glycolipid that occurs in some normal tissues but not in the tissue of tumor origin.

Researchers on glycolipids have been reporting, at an accelerating rate, that tumors contain hitherto completely unknown glycolipids [21-28]. A recent report described four new glycolipids in oat cell carcinoma of human lung, compared with normal human lung [21]. The compounds differed from those of normal tissues mainly in the linkages between the different sugar and sialic acid moieties.

Other novel tumor-associated glycolipids have been found by using monoclonal antibodies, but their structures are still unknown.

\section{Successful therapy of tumors via antibodies to glycolipids}

The use of specific monoclonal antibodies, apparently directed against certain gangliosides, has proved to be an exciting approach [29-32]. Human melanomas produce unusual glycolipids, especially those containing ester groups. Certain antibodies, administered in high dosages, specifically seek out the cancer cells and help to destroy them.

Significantly, some tissues do contain low levels of the same gangliosides but appear to be undamaged by the antibody. As Hakomori has pointed out $[33,34]$, the glycolipids may be less exposed sterically in normal plasma membranes or a critical concentration must be exceeded before antibodies can be significantly damaging. A mixture of both cytotoxic and complement-dependent antibodies would be more useful than either one alone [35].

A similar application to human neuroblastoma cells has been made, based on a monoclonal antibody to ganglioside GD2 [36]. The antibody was tested in nude mice exposed to the human cells and found to suppress tumor establishment, as well as growth. A similar antibody was found to be very useful in a human patient.

Admittedly, this kind of clue indicates only that certain glycolipids occur at an unusually high concentration in the tumor plasma membrane, not that they play a causal role in malignancy. One might be able to achieve similar results with antibodies to any substance that occurs in high concentrations in the tumor surface provided that other tissues contain safely low concentrations. However they do support our suggestion that cancer cells suffer from microsphingolipidoses.

D. Immunodefense by cancer cells due to glycolipids

A major characteristic of cancer is the difficulty that its victims have in generating an immuno- mediated defense against the tumor. The important suggestion has been made that certain glycolipids secreted by tumor cells protect them against the host's immune system by suppressing lymphocyte responses [37-41]. For example [41], murine lymphocytes respond to concanavalin $\mathrm{A}$ by proliferating, but the gangliosides isolated from the ascites fluid induced by lymphoma cells in mice were able to block the effect almost completely. The blockage was effective at less than $28 \mu \mathrm{M}$ ganglioside, a concentration similar to that found in the ascites fluid. The same effect was produced by gangliosides isolated from the lymphoma cells themselves.

Another recent example is ganglioside GDla, which is shed by a mouse fibrosarcoma and which enters the plasma. This glycolipid inhibited the T cell mitogen response as well as the proliferation of a $\mathrm{T}$ cell clone's response to interleukin-2 and the in vitro proliferation of spleen cells [42]. The tumorigenic effect of gangliosides on weakly tumorigenic cells, cited above [15], could be ascribed to an immunosurveillance blockage.

In a review of this important subject [43], Marcus concluded in 1984 that the evidence was so incomplete that one could not take the concept of glycolipid immunomodulation seriously. While the review was realistic in its call for more data, we feel that this strong skepticism was itself based on too many negative assumptions.

\section{E. Glycolipid changes during malignant trans- formation and metastasis}

Cells undergoing developmental or malignant or viral transformation undergo marked changes in the relative proportions of their glycolipids $[3,44-47]$. A good example is the appearance of ganglioside GD3 in rat cells transfected with a transforming gene, while the pretransformed cells do not contain this glycolipid [3]. The introduction of oncogenes into rat 3 Y 1 cells resulted in the appearance of several gangliosides not normally seen in the cells [4]. Different malignancy states of human colonic tumors could be correlated with the expression of the glycolipids responsible for Lewis blood type groups, as revealed with monoclonal antibodies [48].

A study was made with melanoma cells, which progress in vivo through a series of stages of increasing malignancy [49]. As the cells changed, they produced higher and higher concentrations of 9-O-acetyl ganglioside GD3. Normal melanocytes and fibroblasts did not contain a detectable amount of this glycolipid. Another glycolipid, ganglioside GD2, appeared only in advanced tumors and, when the tumor cells at the later stages were cultured, was shed into the culture medium. The authors suggested that the appearance of the unusual gangliosides somehow explains the disappearance of T cells from advanced stage melanomas.

A study of tumorigenicity using human melanoma cells showed that cultured cells having a high level of ganglioside GM2 were able to form tumors in nude athymic mice, whereas cells having a low level of GM2 were not [50]. A graphed line relating tumor size to the sum of GM2 and GD2 concentrations had a remarkably high correlation coefficient, suggesting that GD2 also played some role in the phenomenon. 
The glycolipids of three strains of a murine tumor, one of them nonmetastatic, were compared and the nonmetastatic one was found to have a much lower ganglioside content and a corresponding increase in the level of the precursor glycolipid, GlcCer. There were marked differences in ganglioside distribution [51].

Recently a nonionic minor glycolipid, not yet characterized, was found to be a general marker for proliferating cells, such as transformed human cells [52]. The lipid, apparently present only in human and closely-related primate cell lines, was detected by an antibody. Nonproliferating cells reacted only weakly or not at all.

Studies too numerous to mention, sceking to connect specific gangliosides with binding between cells and penetration of tissues by cells, have been very suggestive. A case could be made for the likelihood that gangliosides are components of the receptors for the adhesion proteins.

\section{F. Glycolipids in plasma as a cancer test}

If tumors do indeed shed novel glycolipids or high concentrations of rare lipids into extracellular fluid, one might hope to detect them in the blood stream. The longed-for diagnostic test for the presence of a tumor by demonstrating the presence in plasma of a strange compound, or an elevated amount of a compound, has been reported a few times. Each time the test is ultimately found to give too many false positive or negative answers, or to be sensitive only to advanced tumors, or to be specific for only a single type of tumor. Recent reports have indicated some success with tests for glycolipids [53-57]. These reports are consistent with the evidence showing that tumors shed copious amounts of glycolipids, which enter plasma quickly enough to make them detectable.

A complex containing much glycolipid (and RNA and polypeptides) has been isolated from the plasma of cancer patients [58]. Apparently it is absent from normal individuals and the authors suggested that the novel material comes from the tumor.

Iguro et al. [59] described a monoclonal antibody which detected a sialylated derivative of lacto- $N$ fucopentaose III (Lewis ${ }^{\mathrm{x}}$ ) in the blood of $26 \%$ of their cancer patients. None of their noncancerous patients yielded a positive response except for $17 \%$ of those with tuberculosis.

Another monoclonal antibody, against ganglioside GD2, reacted highly with almost every child with neuroblastoma but not with children bearing other types of tumors or with normal controls [60]. In one patient, the level of serum GD2 followed the regression of the tumor during therapy.

A recently described test for cancer [61] involved analysis of the plasma lipids with a nuclear magnetic spectrometer. The change in lipids during cancer development (and in the reverse direction during treatment) was not examined chemically so the nature of the abnormality is unknown, but the test was unusually accurate and specific. It is possible that the change in NMR spectrum was due to the presence of a glycolipid.

Ascitic fluids from patients with cancer contain glycolipids, some of which are not present in the plasma [62]. The latter are presumably shed by the tumor itself.

Since different tumors shed different glycolipids. a generalized test (such as total plasma sialic acid or lipid-bound sialic acid) might have only limited value. Chromatographic analysis, combined with monoclonal antibodies for individual plasma glycolipids, seems essential.

\section{G. Abnormal levels of glycolipid-metabolizing enzymes in cancer}

Since abnormal glycolipids occur in tumors, it is not surprising to find new enzymes or changed levels of the enzymes responsible for their metabolism

Human leukocytes from myelogenous leukemia patients were found to have three times the normal level of glucosidase, the enzyme which degrades GlcCer [63]. A study of liver preneoplastic nodules induced by a carcinogen showed that a galactosyltransferase acting on ganglioside GM2 was somewhat higher in the nodules of grade II; about 4.6 times as active as normal liver [64]: Smaller nodules showed normal or subnormal specific activities.

Assay of a rat galactosyltransferase which acts on glycolipids showed that normal liver had about onetenth of the activity when compared with hepatoma [65].

A study of various glycosidases in human colon and breast showed markedly higher values in malignant tissue for $\beta$-galactosidase, $\beta$-acetylgalactosaminidase, $\alpha$-mannosidase and a neuraminidase [66]. The region considered to be normal was taken from the tissue adjacent to the tumor. Important control measures, to rule out indirect cancer effects, were made for DNA, protein, and (by others) mitotic rate. Some hydrolases were not elevated

Examination of rats with metastasizing mammary tumors showed that the plasma level of a sialyltransferase was above normal and that the cnzyme concentration in microsomes from the tumors was six times as high as in nonmetastasizing tumors [67]. The elevated plasma values indicate that tumors shed not only glycolipids but also some of their enzymes.

The induction of a fucosyltransferase and of a galactosyltransferase occurred in the precancerous liver of rats that were fed a carcinogen [68]. These changes were accompanied by the accumulation of certain glycolipids as the liver moved toward the hepatomic state. Similar appearance of a new $N$ acetylglucosaminyltransferase was seen in a human tumor [69].

The appearance of increased levels of glycolipidmctabolizing enzymes seems to contradict our suggestion that tumors lack a specific glycolipid hydrolase. However such a phenomenon has been observed in the case of sphingolipidoses, where a genetic defect in one hydrolase somehow produces increased levels of other sphingolipid hydrolases.

The ability of tumors to synthesize lipids de novo seems to be relatively low and they apparently have to requisition preformed lipids from the host. Tumors absorb triglycerides quite readily [70] and secrete lipotrophic factors which draw the host's fat into the blood, allowing it to be taken up by the tumor $[71,72]$. The fatty acids thus stolen are pre- 
sumably also available for the synthesis of glycolipids (both the sphingol and acyl moieties). It is possible that the host also furnishes intact glycolipids (such as GlcCer), which are found in the plasma lipoproteins. Uptake of host lipids may reflect the importance of shedding certain glycolipids to the tumor's survival.

\section{H. Biological effects of glycolipids}

Gangliosides of different types have been connected to many phenomena: complex formation with cholera toxin, Sendai virus, interleukin, and epidermal growth factor, promotion of neuronal growth, interaction with the peripheral nerve growth factor, cell adhesion, induction of growth or developmental changes, and protein kinase stimulation or inhibition.

A study with murine macrophages showed that addition to the medium of the primary glycolipid, GlcCer, caused the cells to form and release increased amounts of interleukin-1 [73]. By way of comparison for specificity, the authors showed that other sphingolipids had no such effect. Human blood monocytes behaved like macrophages. A similar increase in interleukin formation occurred when phorbol diester was added to the macrophage medium. The similarity between GlcCer and phorbol ester effects is intriguing although there seems to be no obvious structural similarity. Recently, our inhibitor of GlcCer synthesis (see Section I) was found to destroy the proliferative response of $T$ cells to interleukin-2, apparently by eliminating glycolipids essential for the action of the IL-2 receptor [74].

Other reports have shown that glycolipids can be influenced by substances which enhance differentiation. Phorbol diester, added to cultured CEM-2 leukemia cells, produced an increased concentration of the nonionic glycolipids, hexosylceramide and lactosylceramide, as well as ganglioside GM3 [75]. Perhaps the increases were the result of a direct or indirect inhibition by diester of the enzyme, GlcCer glucosidase, or stimulation of the glucosyltransferase that makes GlcCer. Such a phenomenon would explain some stimulating effects of phorbol esters. Moskal et al. [76] have found phorbol ester to produce a $>5$-fold increase in sialyltransferase of NIL 8-HSV cells.

Gangliosides have also been shown to form a complex with interferon type I (not with type II), rendering the interferon unable or less able to block viral replication within mouse LY cells [77].

\section{Therapeutic approaches through the glycolipids}

This brief survey and set of hypotheses point to the need to synthesize drugs which can interfere with the glycolipids. The evidence cited above, particularly in Sections $\mathrm{A}, \mathrm{B}, \mathrm{D}$, and $\mathrm{E}$, gives strong support for the idea that cancer is the result of a microsphingolipidosis. While it is possible to hypothesize that the glycolipid changes and effects are epiphenomena, one must disregard many of the published reports.

The typical biological processes of the glycolipids

* Boland CR, Deshmukh GD, Inokuchi 1 and Radin NS, unpublished work. are (i) synthesis from nonglycolipid precursors and from lower glycolipids, (ii) hydrolytic degradation of higher to lower glycolipids and then to ceramide, and (iii) binding by specific proteins for the formation of membrane-bound receptors, or binding by enzymes in order to modulate their activities, or binding by plasma membrane proteins to form recognition complexes or membrane stabilization complexes, or binding by transport proteins in the plasma and in cell cytosol. Blockage of these processes could be accomplished by the administration of synthetic analogs of the glycolipids, as needed for a particular kind of cancer.

We synthesized an inhibitor of GlcCer synthetase in order to block process "i" and found it to have good antitumor activity against the Ehrlich ascites tumor in vivo [16]. The effectiveness of the drug was reduced by co-injecting GlcCer, as one might predict. Moreover the injection of GlcCer into untreated mice stimulated tumor growth $>50 \%$ (the closely related sphingolipid, galactosylceramide, had no effect). These observations support the hypothesis that glycolipid formation is essential for tumor proliferation. Preliminary data also indicate the ability to block the development of a human colonic tumor in athymic mice. ${ }^{*}$

Process "ii" should not be blocked, since it may lead to increased glycolipid accumulation. Another stage of glycolipid synthesis that might usefully be interfered with is prior to ceramide formation, either in the transfer of fat from the host or in its utilization to make sphingols or ceramide.

Some investigators have suggested that cancer cells produce strange or greatly increased amounts of glycolipids because the gene for a glycolipid synthetase is derepressed. If this is correct, it still makes sense to block those synthetases by an appropriate drug.

One may conclude from in vitro uptake studies that all cells have the ability to absorb glycolipids from the medium. In the case of cancer cells, the source would be plasma lipoproteins or ascites fluid. In order to starve the tumor, one should design inhibitors of glycolipid synthetases that act on human enzymes, as well as tumor enzymes.

One should aim not only to design a synthetase inhibitor but also, as is well known in pharmacology, to make an artificial substrate which might be converted enzymatically by the tumor to a glycolipidlike synthetase inhibitor or destabilizing component of a glycolipid-containing complex.

Even if a particular inhibitor of glycolipid synthesis is only partially effective, it could act synergistically with other drugs having a different mode of action. Mixtures of drugs are usually used in current anticancer therapy.

Few attempts, in laboratories other than this one, have been made to use specific drugs to directly lower the levels of tissue glycolipids and to look for changes in cell properties. Sundaram and Lev [78] have shown that an antibiotic, cycloserine, can block sphingosine biosynthesis in vivo and, therefore, block glycolipid synthesis. Various substances that block the biosynthesis of glycoproteins, such as tunicamycin or monensin, have been tested for their effects on glycolipid synthesis. For example, tuni- 
camycin inhibited ganglioside and neutral glycolipid synthesis in neuronal cells [79]. Monensin caused accumulation of GlcCer and lactosylceramide in human fibroblasts [80] while apparently inhibiting the synthesis of the higher glycolipids in other cells [81]. 2-Deoxy-D-glucose was found to inhibit GlcCer synthesis in BHK-21 cells [82], apparently by forming a deoxyglucose nucleotide which inhibited glucosyltransferase. These compounds may have merit in treating cancer if combined with a more specific inhibitor of glycolipid synthesis.

A designer of an inhibitor of glycolipid synthesis must also consider the "rescue" problem: how to treat a patient who has been overdosed with the inhibitor. In the case of a drug which blocks GlcCer synthesis, this could be done with an injection of GlcCer or conduritol B epoxide, which prevents the degradation of endogenous GlcCer. It might also be possible to help the patient without hindering chemotherapy against the tumor by injecting a rescue glycolipid, such as a ganglioside which is particularly needed by the host but which does not provoke tumor growth

While the ideal anti-glycolipid drug should kill all the cancer cells, it is common for antineoplastics to leave some cryptic surviving cells. The second ideal property, in view of the evidence in Section $D$, is interference with glycolipid shedding and consequent freedom from the host's immunosurveillance system. An experimental test of the latter property could be run by giving surviving test animals a second inoculation of the same tumor cells. If the drug has helped the animal's immune response, the second set of cancer cells should not proliferate, even without drug treatment. We observed this kind of immunity against Ehrlich ascites cells with our drug [16]. Of course more specific measurements of immune response should be run.

The drug must not kill all of the tumor cells too quickly or the host will not have cnough exposure time to develop antibodies. The complexity of this requirement is evident when one considers the different types of antigen and antibody, as well as the antibody concentration at the site of the tumor. A detailed study of L 1210 cell rejection concluded that prolonged mouse survival required development of a high level of $\operatorname{IgG}_{2 \mathrm{a}}$ anti-tumor antibodies within an adequate time [83].

Acknowledgements-This work was supported by the US Public Health Service, Grant HD07406, the University of Michigan Cancer Center, and the University of Michigan Cancer Institute.

\section{REFERENCES}

1. Gallic BL and Worton RG, Somatic events unmask recessive cancer genes to initiate malignancy. $J$ Cell Biochem 32: 215-222, 1986.

2. Murphree AL and Benedict WF, Retinoblastoma: clues to human oncogenesis. Science 223: 1028-1033, 1984.

3. Nakakuma H, Sanai $Y$, Shiroki $K$ and Nagai $Y$, Generegulated expression of glycolipids: appearance of GD3 ganglioside in rat cells on transfection with trans- forming gene $\mathrm{El}$ of human adenovirus type 12 DNA and its transcriptional subunits. $J$ Biochem (Tokyo) 96: 1471-1480, 1984.

4. Nagai $Y$, Nakaishi $H$ and Sanai $Y$, Gene transfer as a novel approach to the gene-controlled mechanism of the cellular expression of glycosphingolipids. Chem Phys Lipids 42: 91-103, 1986

5. Burstein $Y$, Rechavi G, Rausen AR, Frisch B and Spirer Z, Association of Gaucher's disease and lymphoid malignancy in 2 children. Scand J Haematol 35: 445-447, 1985.

6. Shoenfeld Y, Berliner S, Pinckas J and Beutler E, The association of Gaucher's disease and dysproteinemias. Acta Haematol (Basal) 64: 241-243, 1980

7. Fox H, McCarthy P, Andre-Schwartz J, Shoenfeld $Y$ and Miller KB, Gaucher's disease and chronic lymphocytic leukemia. Possible pathogenetic link between Gaucher's disease and B-cell proliferations? Cancer 54: 312-314, 1984.

8. Brady $\mathrm{RO}$ and Barranger JA, Glucosylceramide lipidosis: Gaucher's disease. In: The Metabolic Basis of Inherited Disease (Eds. Stanbury JB, Wyngaarden $\mathrm{JB}$, Fredrickson DS, Goldstein JL and Brown MS), 5th Edn, pp. 842-856. McGraw-Hill, New York, 1983.

9. Datta SC and Radin NS, Glucosylceramide and the level of the glucosidase-stimulating proteins. Lipids $\mathbf{2 1}$ : 702-709, 1986.

10. Roisen FJ, Bartfeld H, Nagele R and Yorke G, Ganglioside stimulation of axonal sprouting in vitro. Science 214: $577-578,1981$

11. Tsuji S, Arita $M$ and Nagai $Y, G Q 1 b$, a bioactive ganglioside that exhibits novel nerve growth factor (NGF)-like activities in the two neuroblastoma cell lines. J Biochem (Tokyo) 94: 303-306, 1983.

12. Spiegel S, Fishman PH and Weber RJ, Direct evidence that endogenous GM1 ganglioside can mediate thymocyte proliferation. Science 230: 1285-1287, 1985.

13. Kuroki T, Ito T, Hosomi J, Munakata K, Uchida T and Nagai Y. Cell AMP as a mitotic signal for epidermal keratinocytes, but not for dermal fibroblasts. Cell Struct Funct 7: 295-305, 1982.

14. Alessandri $G$, Filippeschi S, Sinibaldi $P$, Mornet $F$, Passera P, Spreafico F, Cappa PM and Guillino PM, Influence of gangliosides on primary and metastatic neoplastic growth in human and murine cells. Cancer Res 47: 4243-4247, 1987.

15. Ladisch S, Kitada S and Hays EF, Gangliosides shed by tumor cells enhance tumor formation in mice. J Clin Invest 79: 1879-1882, 1987.

16. Inokuchi $J$ and Radin NS, Antitumor activity via inhibition of glycosphingolipid biosynthesis. Cancer Lett 38: 23-30, 1987.

17. Vaughn CB, Weinstein R, Bond B, Rice R, Vaughn RW, McKendrick A, Ayad G, Rockwell MA and Rocchio R, Ferritin content in human cancerous and noncancerous colonic tissue. Cancer Invest 5: 7-10, 1987.

18. Berra B, Riboni L, De Gasperi R, Gaini SM and Ragnotti G, Modifications of ganglioside patterns in human meningiomas. $J$ Neurochem 40: 777-782, 1983.

19. Siddiqui B, Buehler J, DeGregorio MW and Macher BA, Differential expression of ganglioside GD3 by human leukocytes and leukemia cells. Cancer Res 44: $5262-5265,1984$

20. Schengrund C, Repman MA and Schochat SJ, Ganglioside composition of human neuroblastomas. Cancer 56: $2640-2646,1985$.

21. Hanquing $\mathrm{H}$, Avrova $\mathrm{N}$, Mansson $\mathrm{J}$, Molin $\mathrm{K}$ and Svennerholm L, Gangliosides and neutral glycosphingolipids of normal tissue and oat cell carcinoma of human lung. Biochim Biophys Acta 878: 360-370, 1986.

22. Taki $T$, Hirabayashi $Y$, Ishikawa $H$, Ando S, Kon $K$, Tanaka $Y$ and Matsumoto $M, A$ ganglioside of rat 
ascites hepatoma AH7974F cells. Occurrence of a novel disialoganglioside $(\mathrm{GD} 1 \alpha)$ with a unique $N$. acetylneuraminosyl $\quad(\alpha 2-6)-N$-acetylgalactosamine structure. I Biol Chem 261: 3075-3078, 1986.

23. Fukuda MN, Bothner B, Lloyd KO, Rettig WJ, Tiller PR and Dell A, Structures of glycosphingolipids isolated from human embryonal carcinoma cells. $J$ Biol Chem 261: 5145-5153, 1986.

24. Fukuda MN, Dell A, Tiller PR, Varki A, Klock JC and Fukuda M, Structure of a novel sialylated fucosyl lacto$\mathrm{N}$-nor-hexaosylceramide isolated from chronic myelogenous leukemia cells. I Biol Chem 261: 2376-2383, 1986.

25. Yang $\mathrm{H}$ and Hakomori S, A sphingolipid having a novel type of ceramide and lacto- $N$-fucopentaose III. $J$ Biol Chem. 246: 1192-1200, 1971.

26. Nudelman E, Fukushi $Y$, Levery SB, Higuchi $T$ and Hakomori S, Novel fucolipids of human adenocarcinoma: disialosyl Le antigen of human colonic adenocarcinoma and the monoclonal antibody (FH7) defining this structure. I Biol Chem 261: 5487-5495, 1986.

27. Nudelman E, Levery SB, Kaizu T and Hakomori S, Novel fucolipids of human adenocarcinoma: characterization of the major $\mathrm{Le}^{y}$ antigen of human carcinoma as trifucosylnonaosyl $\mathrm{Le}^{\mathrm{y}}$ glycolipid. $J$ Biol Chem 261: 11247-11253, 1986

28. Kiguchi K, Iwamori M, Nagai Y, Eto $Y$ and Akatsuka $J$, Characterization of glycosphingolipids from cells of various types of human leukemia: occurrence of two glycosphingolipids, one reacting with the anti-asialo GM1 antibody and one with anti-Forssman antibody. Gann 74: 382-390, 1983.

29. Young WW Jr and Hakomori S, Therapy of mouse lymphoma with monoclonal antibodies to glycolipid: selection of low antigenic variants in vivo. Science 211: $487-489,1981$.

30. Hellström I, Brankovan V and Hellström KE, Strong antitumor activities of $\mathrm{IgG3}$ antibodies to a human melanoma-associated ganglioside. Proc Natl Acad Sci USA 82, 1499-1502, 1985.

31. Houghton AN, Mintzer D, Cordon-Cardo C, Welt S, Fliegel B, Vadhan S, Carswell E, Melamed MR, Oettgen HF and Old LJ, Mouse monoclonal IgG3 antibody detecting GD3 ganglioside: a phase I trial in patients with malignant melanoma. Proc Natl Acad Sci USA 82: 1242-1246, 1985.

32. Tsuchida $T$, Saxton RE, Morton $D L$ and Irie RF, Gangliosides of human melanoma. $J$ Natl Cancer Inst 78: $45-54,1987$.

33. Hakomori $S$, Tumor-associated glycolipid antigens, their metabolism and organization. Chem Phys Lipids 42: 209-233, 1986.

34. Hakomori S, Glycosphingolipids. Sci Am 254: 44-53, 1986.

35. Thurin $J$, Thurin $M$, Kimoto $Y$, Herlyn $M$, Lubeck $M D$, EIder DE, Smereczynska $M$, Karlsson $K$, Clark WM Jr, Steplewski Z and Koprowski H, Monoclonal antibody-defined correlations in melanoma between levels of GD2 and GD3 antigens and antibodymediated cytotoxicity. Cancer Res 47: 1229-1233, 1987.

36. Mujoo K, Cheresh DA, Yang HM and Reisfeld RA, Disialoganglioside GD2 on human neuroblastoma cells: target antigen for monoclonal antibody-mediated cytolysis and suppression of tumor growth. Cancer Res 47: 1098-1104, 1987.

37. Hakomori $S$ and Young WW Jr, Tumor-associated glycolipid antigens and modified blood group antigens. Scand J Immunol [Suppl] 6: 97-117, 1978.

38. Esselman WJ and Miller HC, Modulation of B cell responses by glycolipid released from antigen-stimulated cells. I Immunol 119: 1994-2000, 1977

39. Lengle EE, Krishnaraj R and Kemp RG, Inhibition of the lectin-induced mitogenic response of thymocytes by glycolipids. Cancer Res 39: 817-822, 1979 .

40. Whisler RL and Yates AJ, Regulation of lymphocyte responses by human gangliosides. I Immunol 125: 2106-2111, 1980

41. Ladisch S, Gillard B, Wong C and Ulsh L, Shedding and immunoregulatory activity of YAC-1 lymphoma cell gangliosides. Cancer Res 43: 3808-3813, 1983.

42. Frey J, Rintoul D and Fortner GW, Suppression of the immune response by a ganglioside shed from the cell membrane of a progressor UV-induced fibrosarcoma. Fed Proc 46: 1504, 1987.

43. Marcus DM, A review of the immunogenic and immunomodulatory properties of glycosphingolipids. Mol Immunol 21: 1083-1091, 1984.

44. Brady RO and Fishman PH, Biosynthesis of glycolipids in virus-transformed cells. Biochim Biophys Acta 355 . 121-148, 1974.

45. Hildebrand J, Stryckmans PA and Vanhouche J, Gangliosides in leukemic and non-leukemic human leukocytes. Biochim Biophys Acta 260: 272-278, 1972.

46. Breimer ME, Adaptation of mass spectrometry for the analysis of tumor antigens as applied to blood group glycolipids of a human gastric carcinoma. Cancer Res 40: 897-908, 1980.

47. Hakomori S, Structures and organization of cell surface glycolipids. Dependency on cell growth and malignant transformation. Biochim Biophys Acta 417: 55-89, 1975.

48. Kim YS, Yuam M, Itzkowitz SH, Sun Q, Kaizu T, Palekar A, Trump BF and Hakomori S, Expression of $\mathrm{Le}^{y}$ and extended $\mathrm{Le}^{y}$ blood group-related antigens in human malignant, premalignant, and nonmalignant colonic tissues. Cancer Res 46: 5985-5992, 1986

49. Thurin J, Thurin M, Herlyn M, Elder DE, Steplcwski $\mathrm{Z}$, Clark WH Jr and Koprowski H, GD2 ganglioside biosynthesis is a distinct biochemical event in human melanoma tumor progression. FEBS Lett 208: 17...22, 1986.

50. Tsuchida T, Saxton RE and Irie RF, Gangliosides of human melanoma: GM2 and tumorigenicity. $J$ Natl Cancer Inst 78: 55-60, 1987.

51. Laferte S, Fukuda MN, Fukuda M, Dell A and Dennis IW, Glycosphingolipids of lectin-resistant mutants of the highly metastatic mouse tumor cell line, MDAYD2. Cancer Res 47: 150-159, 1987.

52. Dubey DP, Staunton DE, Parekh AC, Schwarting GA, Antoniou D, Lazarus $H$ and Yunis EJ, Unique proliferation-associated marker expressed on activated and transformed human cells defined by monoclonal antibody. J Natl Cancer Inst 78: 203-212, 1987.

53. Kloppel TM, Keenan TW, Freeman MJ and Morre D, Glycolipid-bound sialic acid in serum: increased levels in mice and humans bearing mammary carcinomas. Proc Natl Acad Sci USA 74; 3011-3013, 1977.

54. Lengle EE, Increased levels of lipid-bound sialic acid in thymic lymphocytes and plasma from leukemic AKR/J mice. J Natl Cancer Inst 62: 1565-1567, 1979.

55. Portoukalian $J$, Zingelstein $G$, Abdul-Malak $N$ and Dove $J$, Alteration of gangliosides in plasma and red cells of humans bearing melanoma tumors. Biochem Biophys Res Commun 85: 916-920, 1978.

56. Katopodis N, Hirshaut Y, Geller NL and Stock CC, Lipid-associated sialic acid test for the detection of human cancer. Cancer Res 42: 5270-5275, 1982.

57. Ladisch $S$ and Wu Z-L, Detection of a tumor-associated ganglioside in plasma of patients with neuroblastoma. Lancet I: 136-138, 1985.

58. Wieczorek AJ, Rhyner $\mathrm{C}$ and Block LII, Isolation and characterization of an RNA-proteolipid complex associated with the malignant state in humans. Proc Natl Acad Sci USA 82: 3455-3459, 1985.

59. Iguro T, Wakasaka A. Terasaki PI, Hirota M, Suyama 
N, Fukushima K, Chia D and Kawahara M, Sialylated Lewis ${ }^{\mathrm{x}}$ antigen detected in the sera of cancer patients. Lancet II: 817-818, 1984.

60. Schulz G, Cheresh DA, Varki NM, Yu A, Staffileno LK and Reisfeld RA, Detection of ganglioside GD2 in tumor tissues and sera of neuroblastoma patients. Cancer Res 44: 5914-5920, 1984.

61. Fossel ET, Carr JM and McDonagh J, Detection of malignant tumors. Water-suppressed proton NMR spectroscopy of plasma. New Engl J Med 315: 1369$1376,1986$.

62. Taki T, Kojima S, Seto H, Yamada $H$ and Matsumoto M, Glycolipid composition of ascitic fluids from patients with cancer. $J$ Biochem (Tokyo) 96: 12571265,1984

63. Kampine JP, Brady RO, Yankee RA, Kanfer JN, Shapiro D and Gal AE, Sphingolipid metabolism in leukemic leukocytes. Cancer Res 27: 1312-1315, 1967.

64. Merritt WD, Morre DJ, Doak RL and Keenan TW, Gangliosides of liver tumors induced by $N$-2-fluorenylacetamide III. Galactosyl and sialyl transferases in single carcinomas and nodules. Cancer Biochem Biophys 4: 183-194, 1979.

65. Merritt WD, Morre DJ and Keenan TW, Gangliosides of liver tumors induced by $\mathrm{N}$-2-fluorenylacetamide. II . Alterations in biosynthetic enzymes. $J$ Natl Cancer Inst 60: $1329-1337,1978$.

66. Bossmann HB and Hall TC, Enzyme activity in invasive tumors of human breast and colon. Proc Natl Acad Sci USA 71: 1833-1837, 1974.

67. Bernacki RJ and Kim U, Concomitant elevations in serum sialyltransferase activity and sialic acid content in rats with metastasizing mammary tumors. Science 195: 577-580, 1977.

68. Holmes EH and Hakomori S, Enzymatic basis for changes in fucoganglioside during chemical carcinogenesis. J Biol Chem 258: 3706-3713, 1983.

69. Holmes EH, Hakomori S and Ostrander GK, Synthesis of type 1 and 2 lacto series glycolipid antigens in human colonic adenocarcinoma and derived cell lines is due to activation of a normally unexpressed $\beta 1 \rightarrow 3 N$ acetylglucosaminyltransferase. $J$ Biol Chem 262: 15649-15658, 1987.

70. Hoffmann CJK, Paweletz N, Friedel R and Haeffner EW, Structural and functional alterations of lipiddepleted ascites tumor cells in culture. Eur J Cell Biol 33: 66-74, 1984.

71. Kitada S, Hays EF, Mead JF and Zabin I, Lipolysis induction in adipocytes by a protein from tumor cells. $J$ Cell Biochem 20, 409-416, 1982.

72. Masuno H, Yamasaki N and Okuda H, Purification and characterization of a lipolytic factor (toxohormoneL) from cell-free fluid of ascites sarcoma 180. Cancer Res 41: 284-288, 1981.

73. Gery I, Zigler JS Jr, Brady RO and Barranger JA Selective effects of glucocerebroside (Gaucher's storage material) on macrophage cultures. $J$ Clin Invest 68: $1182-1189,1981$

74. Felding-Habermann B, Handa K, Hakomori S and Radin N, Modulation of lymphocyte response and IL2-dependent $T$ cell proliferation by gangliosides and their derivatives and by inhibitor of ceramide glycosylation. FASEB J 2: A876, 1988.

75. Kiguchi K, Henning-Chubb $\mathrm{C}$ and Huberman $\mathrm{E}$, Alteration in glycosphingolipid pattern during phorbol-12myristate-13-acetate-induced cell differentiation in human T-lymphoid leukemia cells. Cancer Res $\mathbf{4 6}$ : 3027-3033, 1986.

76. Moskal JR, Lockney MW, Marvel CC, Trosko JE and Sweeley CC, Effect of retinoic acid and phorbol-12myristate-13-acetate on glycosyltransferase activities in normal and transformed cells. Cancer Res 47: 787-790, 1987.

77. Aoyagi $T$, Okuyama A, Umezawa $H$, Iwamori $M$, Nagai Y, Suzuki J, Ishii A and Kobayashi S, Interaction of mouse type I and type II interferon with gangliosides. Biochem Int 2: 187-193, 1981.

78. Sundaram KS and Lev M, Inhibition of sphingolipid synthesis by cycloserine in vitro and in vivo. J Neur ochem 42: $577-581,1984$

79. Guarnaccia SP, Shaper JH and Schnaar RL, Tunicamycin inhibits ganglioside biosynthesis in neuronal cells. Proc Natl Acad Sci USA 80: 1551-1555, 1983.

80. Saito M, Saito $M$ and Rosenberg A, Action of monensin, a monovalent ionophore, on cultured human fibroblasts: evidence that it induces high cellular accumulation of glucosyl- and lactosylceramide (glucoand lactocerebroside). Biochemistry 23: 1043-1046, 1984.

81. Miller-Prodraza $\mathbf{H}$ and Fishman PH, Effect of drugs and temperature on biosynthesis and transport of glycolipids in cultured neuroblastoma cells. Biochim Biophys Acta 804: 44-51, 1984.

82. Ray EK and Blough HA, The effect of herpesvirus infection and 2-deoxy-D-glucose on glycosphingolipids in BHK-21 cells. Virology 88: 118-127, 1978.

83. Ciavarra RP and Terres $G$, Immune rejection mechanisms in murine leukemia. I. Timing of tumor cell rejection process relative to the development of humoral and cell-mediated cytotoxic immune responses. Int $J$ Cancer 34: 681-688, 1984. 